\title{
Sensitivity Analysis in Parameter Calibration of the WEAP Model for Integrated Water Resources Management in Unda Watershed
}

\author{
I Gusti Agung Putu Eryani ${ }^{1, *}$, Made Widya Jayantari ${ }^{2}$, I Kadek Merta Wijaya ${ }^{3}$ \\ ${ }^{1}$ Department of Civil Engineering, Warmadewa University, Denpasar, 80239, Indonesia \\ ${ }^{2}$ Department of Civil Engineering, Universitas Pendidikan Nasional, Denpasar, 80224, Indonesia \\ ${ }^{3}$ Department of Architecture, Warmadewa University, Denpasar, 80239, Indonesia
}

Received November 3, 2021; Revised January 8, 2022; Accepted February 8, 2022

\section{Cite This Paper in the following Citation Styles}

(a): [1] I Gusti Agung Putu Eryani, Made Widya Jayantari, I Kadek Merta Wijaya , "Sensitivity Analysis in Parameter Calibration of the WEAP Model for Integrated Water Resources Management in Unda Watershed," Civil Engineering and Architecture, Vol. 10, No. 2, pp. 455-469, 2022. DOI: 10.13189/cea.2022.100206.

(b): I Gusti Agung Putu Eryani, Made Widya Jayantari, I Kadek Merta Wijaya (2022). Sensitivity Analysis in Parameter Calibration of the WEAP Model for Integrated Water Resources Management in Unda Watershed. Civil Engineering and Architecture, 10(2), 455-469. DOI: 10.13189/cea.2022.100206.

Copyright $\odot 2022$ by authors, all rights reserved. Authors agree that this article remains permanently open access under the terms of the Creative Commons Attribution License 4.0 International License

\begin{abstract}
WEAP or Water Evaluation and Planning is a model that is used to simulate integrated water resources management. To get a model that is able to represent the real condition, a calibration process is needed. This study aims to determine the optimum parameter value through sensitivity analysis and to determine the parameter value to obtain the optimum model reliability value during the calibration process. Based on the sensitivity analysis process for several calibration parameters of the WEAP model, it is found that some parameters have similar characteristics. Change in $\mathrm{Z}_{1}$, DWC, RRF, RZC value is directly proportional to the RMSE value, the greater the parameter value, the greater the RMSE value obtained. Whereas change in $Z_{2}$, DC, SWC, PFD value is inversely proportional to the RMSE value, the larger the parameter value, the smaller the RMSE value obtained. After the sensitivity analysis was carried out, the efficiency coefficient of the Nash Sutcliffe model was obtained 0.512 which was satisfactory. The Index of Agreement and the correlation coefficient of calibration also show good results with values of 0.848 and 0.743 . From these results, it can be concluded that the WEAP model for the Unda watershed is satisfactory.
\end{abstract}

Keywords Integrated Water Resources Management, WEAP, Calibration, Sensitivity Analysis

\section{Introduction}

Climate change, increasing population, land use changes can increase water pressure on sustainability in the future [1][2]. To address future water stress, the sustainable use of water resources on a local and global scale is essential [3][4][5]. Analysis and identification of hydrological processes in a watershed is very important to determine the right pattern of water resource management so that it can be sustainable [6]. Due to the complexity of water resource management, models can help to simplify it. To help analyze an integrated water resources management, many integrated water resources management models have been developed, both mathematical models and models in the form of software. WEAP is one of the most widely used integrated water resource management models [7][8][9].

WEAP can integrate the hydrological processes that occur in an area that represents the availability of water in the area with the water needs needed in the area. Then from the existing conditions, several simulations of integrated water resource management can be carried out to see the effect of integrated water resources management on the water allocation that occurs [10]. WEAP also has the advantage that it can simulate integrated water resource management with little or much data. The more and the quality of the data, the WEAP 
model will provide better model reliability. WEAP can also divide water management for various sectors. Therefore, this system is suitable for studying catchments with minimum to moderate data availability [11]. WEAP model can provide a solution to overcome inequalities in water allocation to obtain effective management so as to reduce the level of water shortages in one area and use excess water in other areas so that it can benefit the community [12].

The WEAP model has been used in several cases to manage integrated water resources in several countries. Currently, with the increase in WEAP capabilities, WEAP can already be integrated with several applications such as MODFLOW, QUAL2K, and GIS [15].

In this study, the calibration process of several parameters used in the WEAP algorithm will be carried out by taking the Unda watershed as the research location. Unda watershed is one of the potential watersheds in the province of Bali, Indonesia.

In this study, the process of calibrating several parameters used in the WEAP algorithm is performed using the Unda watershed as the research location. The Unda watershed is one of the potential watersheds in Bali Province [16].

The potential of the Unda catchment area is widely used for irrigation water demand. Despite great potential, some irrigated areas still lack water. Therefore, the use of WEAP as one of the IWRM-based water allocation models in the Unda Basin can reduce the occurrence of water shortages in the irrigated areas of the Unda Basin.

As the available computing power increases and the need to express spatial heterogeneity and physical properties of watersheds increases, more sophisticated hydrological models are being developed [17][18]. This increase in model complexity has exacerbated the burden of calibrating model parameters by significantly increasing the number of parameters that can be set. Therefore, in order to filter out the most important parameters and reduce the parameter size, it is necessary to analyze the sensitivity of the parameters before parameter estimation. Sensitivity analysis and calibration are important part of development of hydrological model [19][20][21][22].

This study aims to determine the optimum parameter value through sensitivity analysis and to determine the parameter value to obtain the optimum model reliability value during the calibration process.

\section{Materials and Methods}

\subsection{Research Location}

In this research, the model that will be created will simulate the water balance of the Unda watershed based on its demands and availability. Water demands will be divided into 2 type that are irrigation water demands and raw water demands. Then the supply will be modeled based on the rain flow model and additional from the spring. In Figure 1, we can see the location of the water demand and water availability of Unda watershed. 


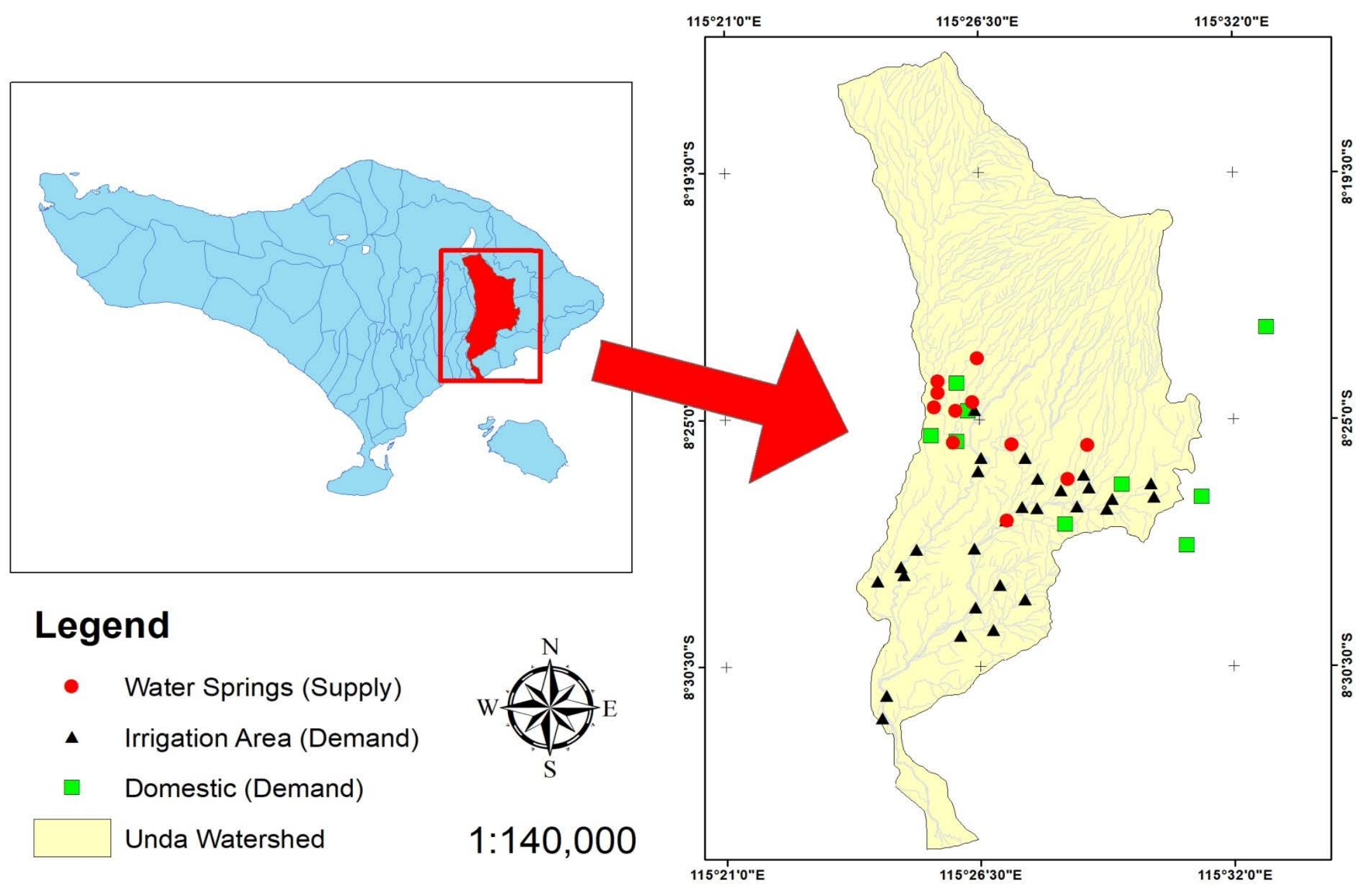

Figure 1. Unda Watershed 


\subsection{Research Materials and Tools}

The tools used to process the data in this study were Ms. Excel 2013 and WEAP version 2019.2. On the other hand, the data required in this study are primary data and secondary data. The primary data is an overview of the current state of the catchment area and assumes modeling, and the secondary data are population, irrigated area, number of livestock, climate data, emission data, and the derived Unda GIS map from relevant institutional and literature studies to determine the factors used for scenario analysis.

\subsection{Research Methods}

This research was conducted by building a WEAP model that starts with the creation of a current account. The current account represents the basic definition of the current water supply system and forms the basis for the analysis of all scenarios. Scenarios are sequential storylines of how future systems might evolve under given socio-economic circumstances and given policy and technological conditions. After creating a current account, water demands and water availability data are entered into the model, followed by calibration and validation. Calibration based on 2012-2014 data. The calibration process is supported by sensitivity analysis to obtain optimal parameter values for best model reliability. More details can be seen in Figure 2.

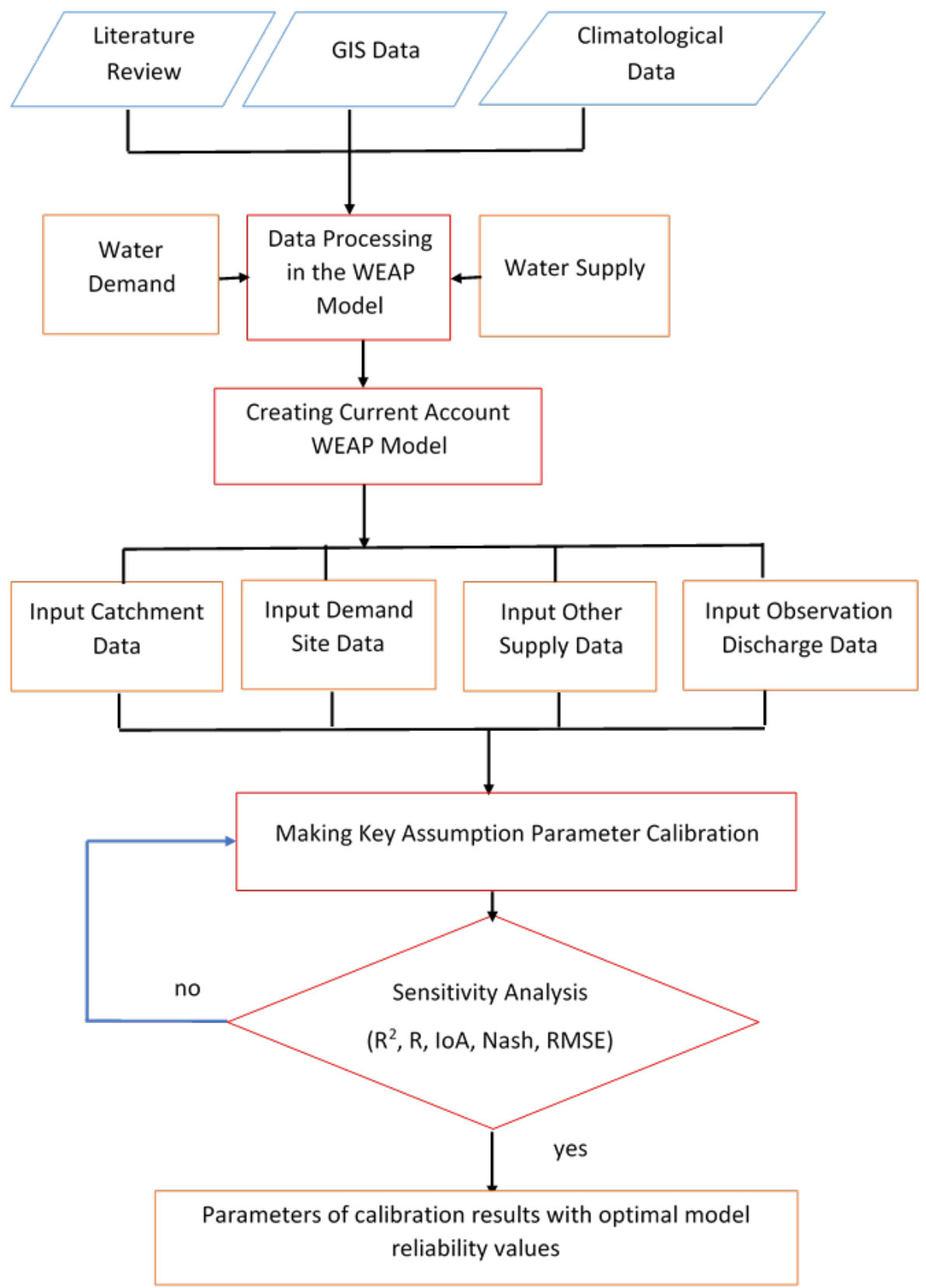

Figure 2. Research Framework 


\subsection{Model Calibration}

\subsubsection{Calibration}

To get a model that fits the actual situation, it is necessary to calibrate the model [23]. Calibration is an iterative process exercise that is used to determine the optimum parameters to obtain a model that is relevant to the actual situation [24]. This process is very important to provide confidence in the simulation results [25].

For the WEAP model where WEAP combines the hydrological process with water allocation, the parameters that can be calibrated are hydrological parameters that greatly affect water availability and play a role in the impact of integrated water resource management and are simulated. Model calibration can be done manually, automatically and a combination of the two methods. Manual calibration using trial and error in parameter adjustment through several simulations.

\subsubsection{Model Reliability Interpretation}

The following tables from Tables 1 and 2 can be used when determining whether a model is feasible or acceptable.

Table 1. The Criteria of Nash-Sutcliffe Efficiency (NSE) Value

\begin{tabular}{|c|c|}
\hline Nash-Sutcliffe Efficiency (NSE) Value & Interpretation \\
\hline$>0.75$ & Well \\
\hline $0.36-0.75$ & Satisfying \\
\hline$<0.36$ & Less satisfactory \\
\hline
\end{tabular}

Source: Motovilov [26]

Table 2. Criteria R Value (Correlation Coefficient)

\begin{tabular}{|c|c|}
\hline Correlation Coefficient Value (R) & Interpretation \\
\hline $0.7<\mathrm{R}<1.0$ & High correlation \\
\hline $0.4<\mathrm{R}<0.7$ & Substantial relationship \\
\hline $0.2<\mathrm{R}<0.4$ & Low correlation \\
\hline $\mathrm{R}<0.2$ & Ignored \\
\hline
\end{tabular}

Source: Suktikno [27]

\section{Result and Discussion}

Eleven hydrological parameters appear in modeling using WEAP, eight of which must be calibrated. The large number of hydrological parameters that must be calibrated will require a long time in the retrying process to obtain optimal conditions. For this reason, it is necessary to analyze the sensitivity of each parameter to determine the main parameters that affect the simulation output. In this modeling, sensitivity analysis is carried out to see the effect of parameter changes on the reliability of the model.

\subsection{Initial Calibration Parameter Value}

At the beginning of the simulation, the parameter values are adjusted to the default WEAP software. The values of these parameters are as in Table 3.

Table 3. Initial Parameter Value (Default)

\begin{tabular}{|c|c|}
\hline Parameter & Default \\
\hline $\mathrm{Z}_{1}$ & $30 \%$ \\
\hline $\mathrm{Z}_{2}$ & $30 \%$ \\
\hline Deep Water Capacity (DWC) & $1000 \mathrm{~mm}$ \\
\hline Deep Conductivity (DC) & $20 \mathrm{~mm} / \mathrm{month}$ \\
\hline Resistance Runoff Factor (RRF) & 2 \\
\hline Root Zone Conductivity (RZC) & $20 \mathrm{~mm} / \mathrm{month}$ \\
\hline Soil Water Capacity (SWC) & $1000 \mathrm{~mm}$ \\
\hline Preferred Flow Direction (PFD) & 0.15 \\
\hline
\end{tabular}

\subsection{Sensitivity Analysis}

This sensitivity analysis is carried out by looking at the streamflow relative to gauge (absolute) in $\mathrm{m}^{3} / \mathrm{s}$, i.e. the absolute difference between the observed streamflow and the streamflow simulated at the node just above the gauge (simulation streamflow result is reduced by observation streamflow).

\subsubsection{Changes in Soil Water Capacity (SWC)}

Soil water capacity is defined as the air holding capacity of topsoil, represented in mm (top "bucket"). SWC values range from 0-1000 $\mathrm{mm}$. 


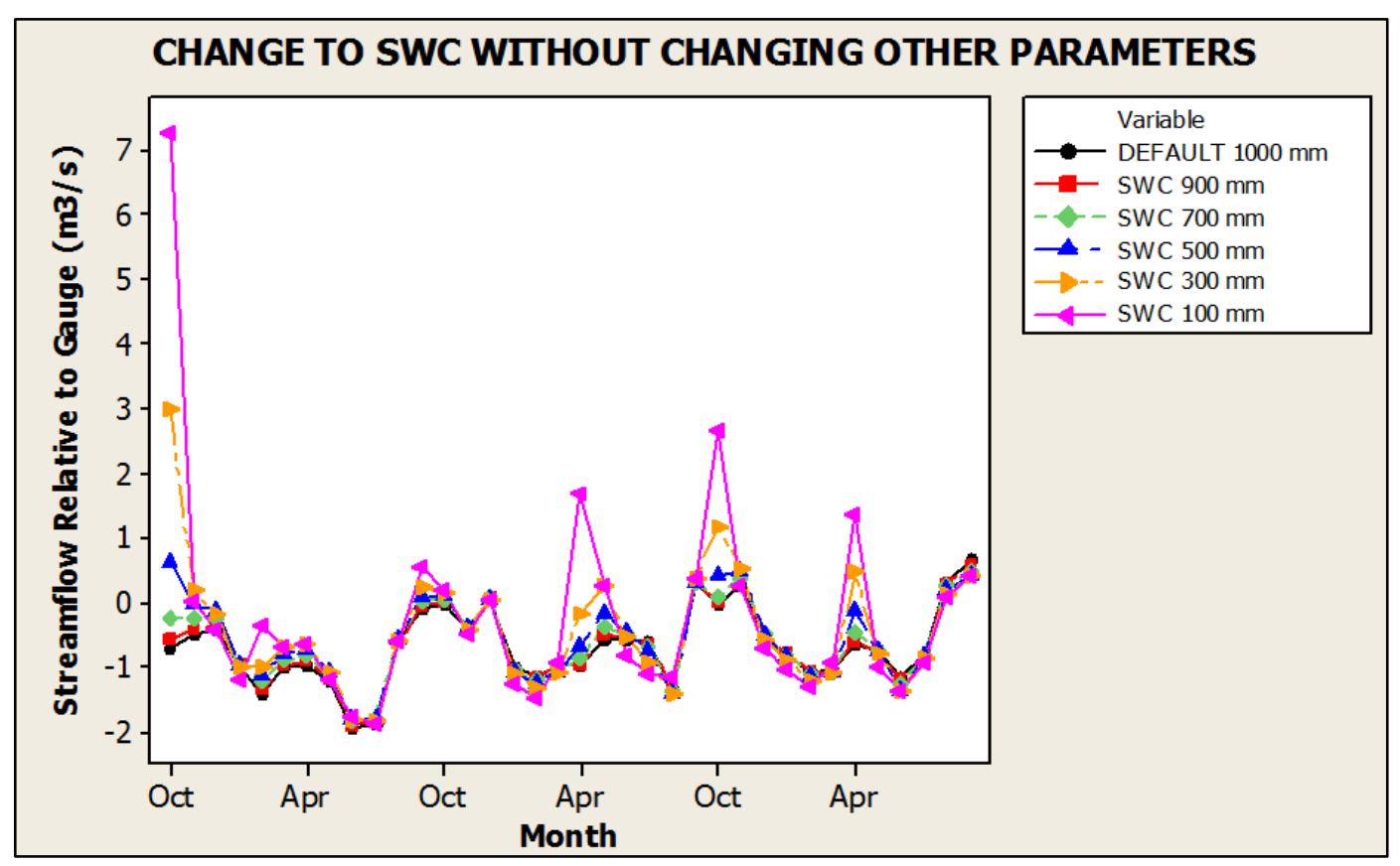

Figure 3. The Relationship of Streamflow Relative to Gauge (Absolute) with Change in SWC

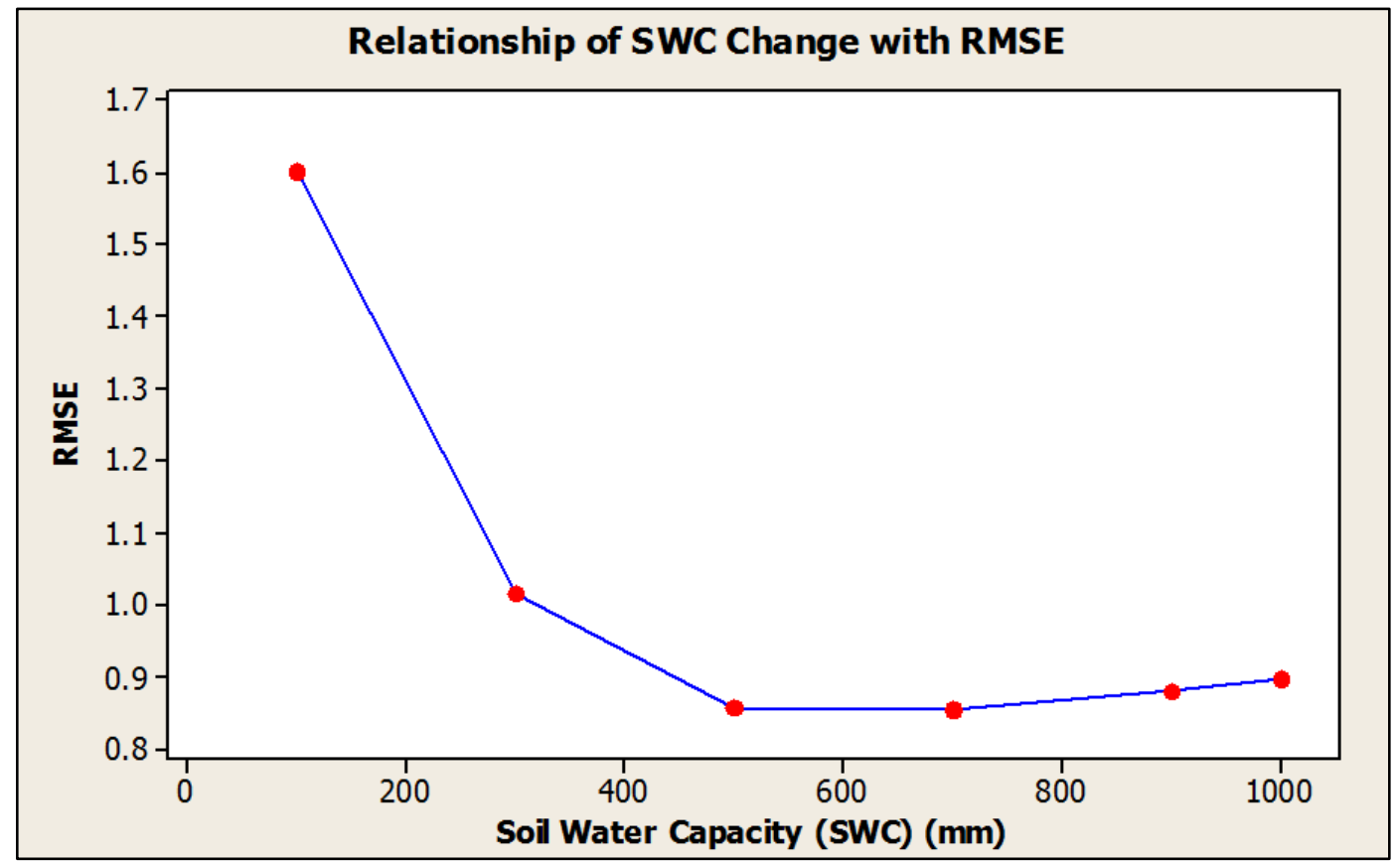

Figure 4. The Relationship of SWC with Root Mean Square Error (RMSE) value

In performing the calibration, the relative to gauge streamflow data can be seen as a reference for the difference between the simulated discharge and the observed discharge. Figure 3 shows the monthly runoff associated with level values from 2012 to 2014 for some scenarios of SWC values.

The sensitivity analysis for the SWC value without changing other parameters can be seen in Figure 4. The root mean square error (RMSE) value for changes in SWC $1000 \mathrm{~mm}-700 \mathrm{~mm}$ tends to decrease, but when the SWC changes towards $100 \mathrm{~mm}$, the RMSE value tends to increase. This shows that a SWC value that is too large will assume a lot of water is accommodated and a SWC value that is too small will make an assumption that a lot of water flows directly. So that in months with rainfall above the average at a small SWC value will produce a large simulation discharge and vice versa.

\subsubsection{Changes in $\mathrm{Z}_{1}$}

The $\mathrm{Z} 1$ value is defined as the relative storage value in the root zone at the beginning of the simulation. The relative storage can be calculated as a percentage of the 
total effective water storage capacity of the root zone. $\mathrm{Z}_{1}$ values can range from $0-100 \%$.

In Figure 5, it can be seen the monthly streamflow relative to gauge values from 2012-2014 for several scenarios of $\mathrm{Z}_{1}$ values.

Almost the same as changes in soil water capacity, changes in $\mathrm{Z}_{1}$ in the simulation model have an optimum RMSE value (the simulation discharge value is closer to the observed discharge) wherein $\mathrm{Z}_{1}$ changes from $100 \%$ to $40 \%$ of the RMSE value (root mean square error) decreases and increases again at the change to $0 \%$ as shown in Figure 6 . In the above-average rain, the value of $Z_{1}$ should be assumed to be relatively small so that the initial relative conditions are still able to absorb water and do not flow directly as a flow rate. When the simulation discharge is lower than the observation, the change in $\mathrm{Z}_{1}$ does not significantly change the simulation discharge, but on the contrary, when the simulation discharge is greater than the observed change, $\mathrm{Z}_{1}$ is very significant.

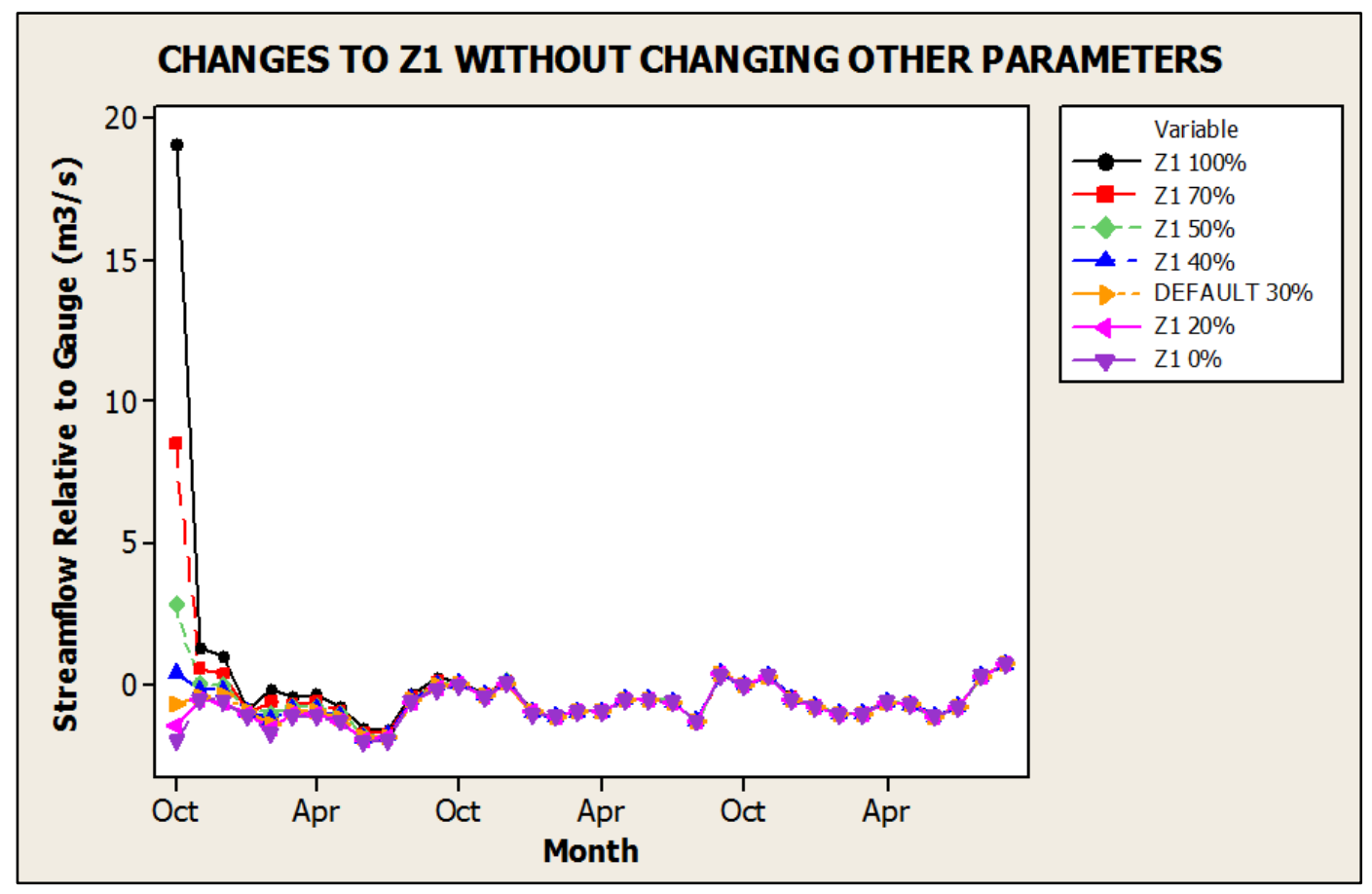

Figure 5. The Relationship of Streamflow Relative to Gauge (Absolute) with Change in $\mathrm{Z}_{1}$

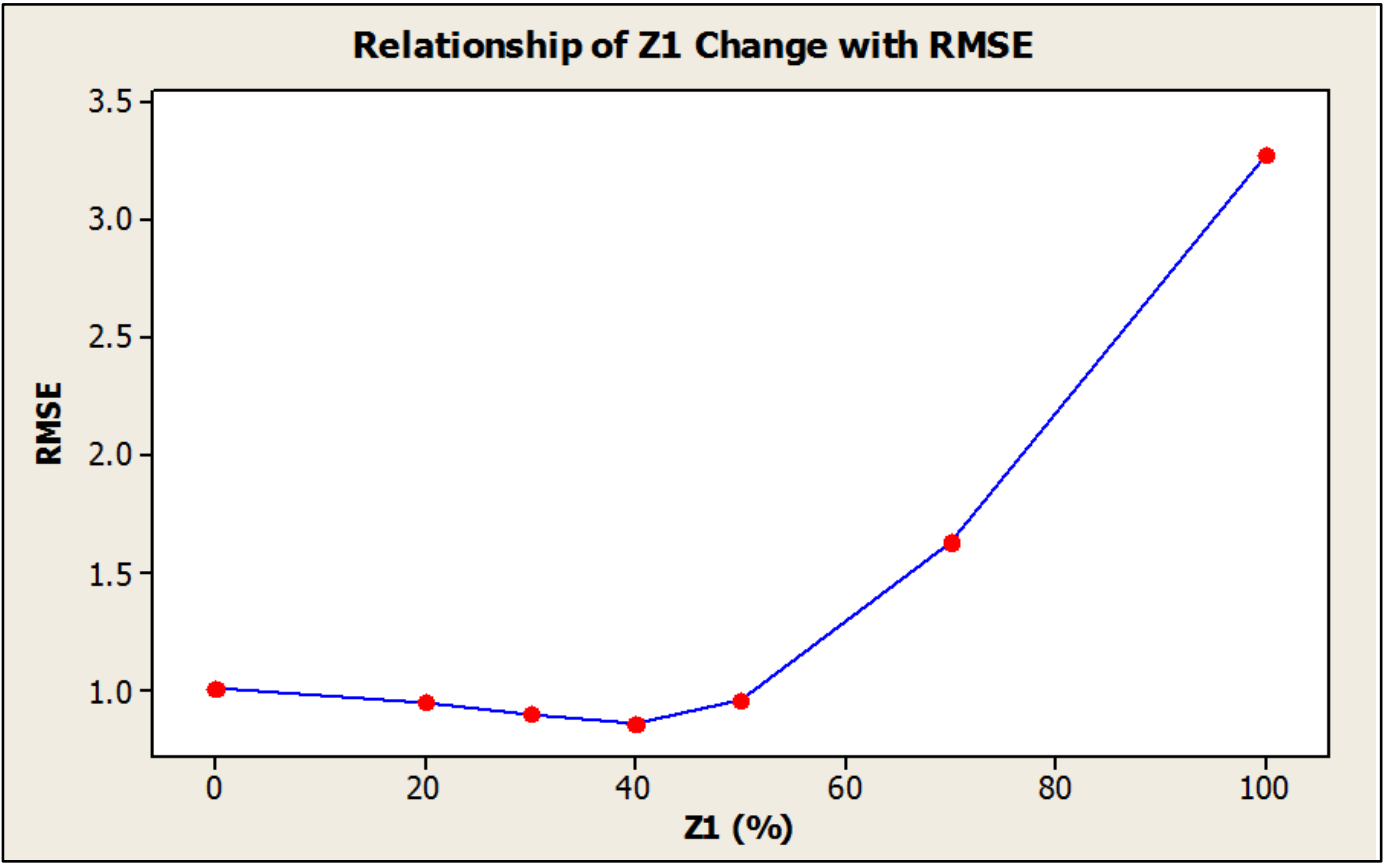

Figure 6. The Relationship of $Z_{1}$ with Root Mean Square Error (RMSE) value 


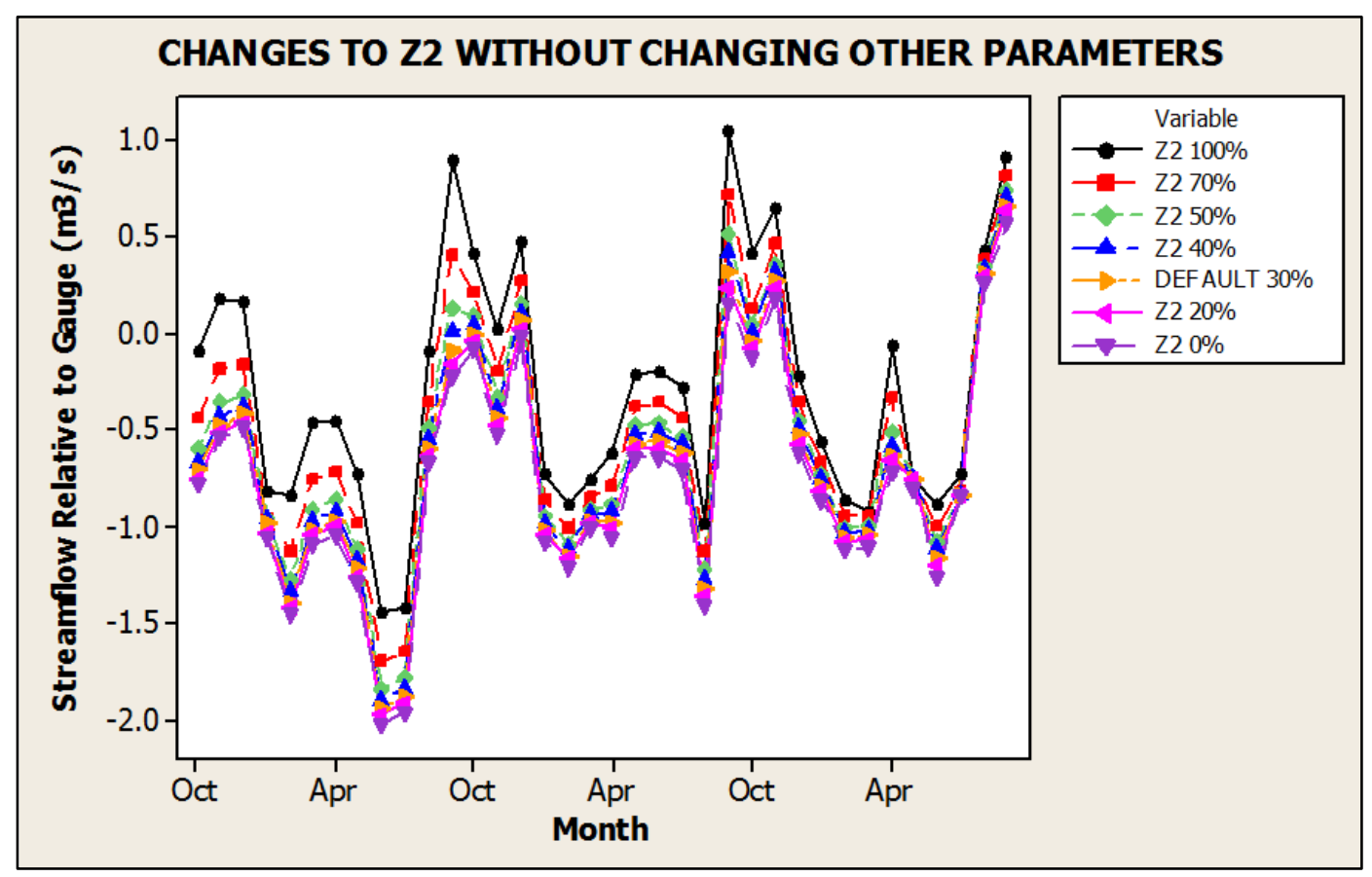

Figure 7. The Relationship of Streamflow Relative to Gauge (Absolute) with Change in $\mathrm{Z}_{2}$

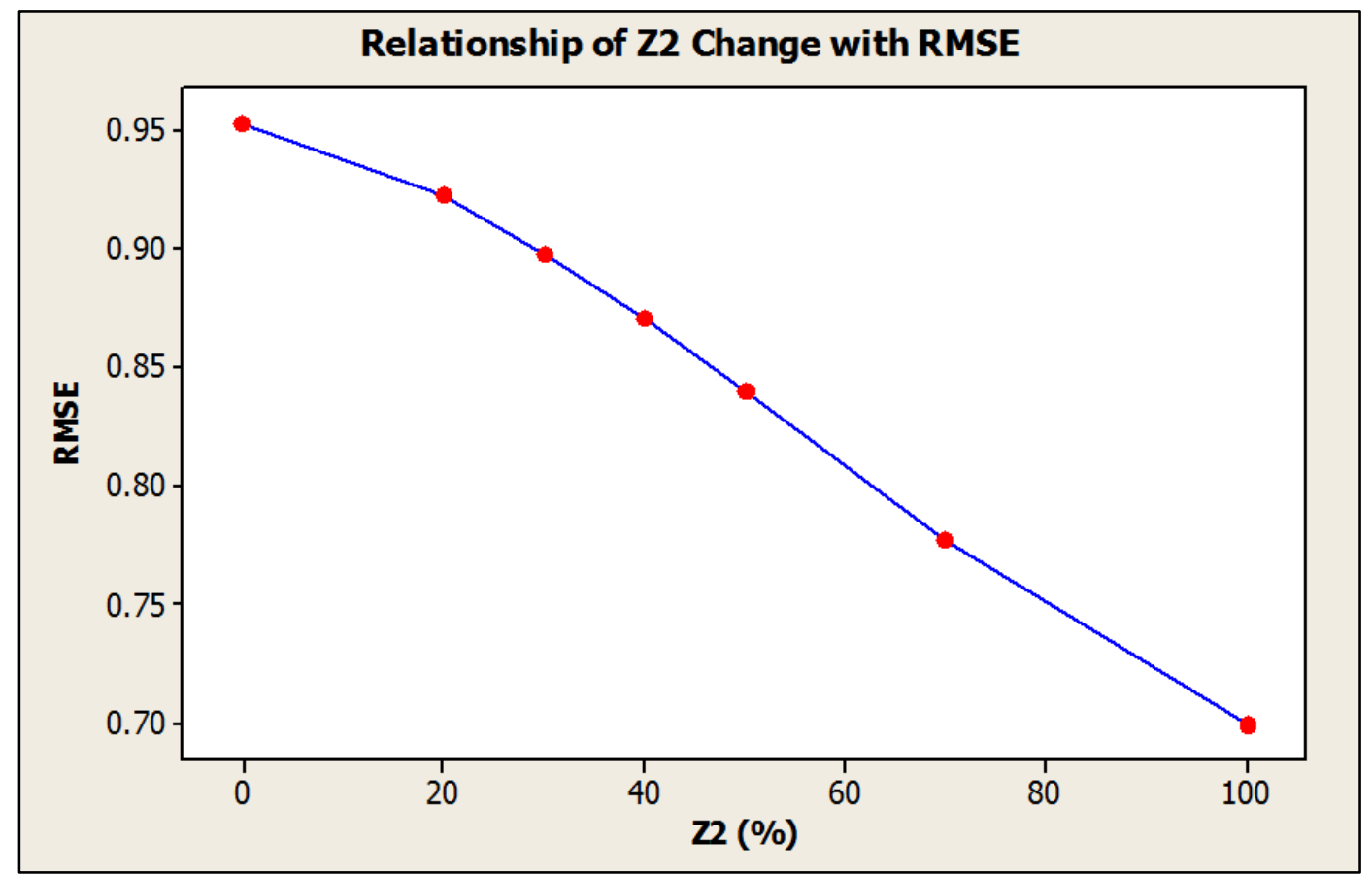

Figure 8. The Relationship of $Z_{2}$ with Root Mean Square Error (RMSE) value

\subsubsection{Changes in $Z_{2}$}

The $Z_{2}$ value is defined as the relative storage value given as a percentage of the lower total effective soil storage (deep water capacity). If the research site models the runoff/infiltration link to the groundwater node, this parameter can be ignored. $Z_{2}$ values ranged from $0-100 \%$.

In Figure 7, it can be seen the monthly streamflow relative to gauge values from 2012-2014 for several scenarios of $Z_{2}$ values.
The trend of changes in $\mathrm{Z}_{2}$ has a slightly different RMSE trend with changes in SWC and $Z_{1}$, as shown in Figure 8 the RMSE value of $Z_{2}$ tends to increase along with a decrease in the value of $Z_{2}$. Changes in $Z_{2}$ do not have significant changes, because the values do not vary between soil class types.

\subsubsection{Changes in Preferred Flow Direction (PFD)}

The preferred flow direction value is defined as the preferred flow direction, where a value of 1.0 means $100 \%$ 
horizontal flow direction and 0 means $100 \%$ vertical flow. Outflow from the root zone layer (top "bucket") is separated by interflow and flow to the lower soil layer (bottom "bucket") or groundwater with this PFD value. Different types of soil classes will cause variations in the PFD value.

In Figure 9, it can be seen the monthly streamflow relative to gauge values from 2012-2014 for several scenarios of PFD values.
The trend of changes in preferred flow direction value has a decreasing RMSE trend as PFD value increases as shown in Figure 10. This PFD simulation shows that when the flow direction is 1 (100\% horizontal) and $0(100 \%$ vertical). At the time of simulation, the decrease in the PFD value makes the simulation discharge smaller so that when the month has rain below the average, it must be assumed to have a large PFD so that the simulation discharge value can be closer to the observed discharge.

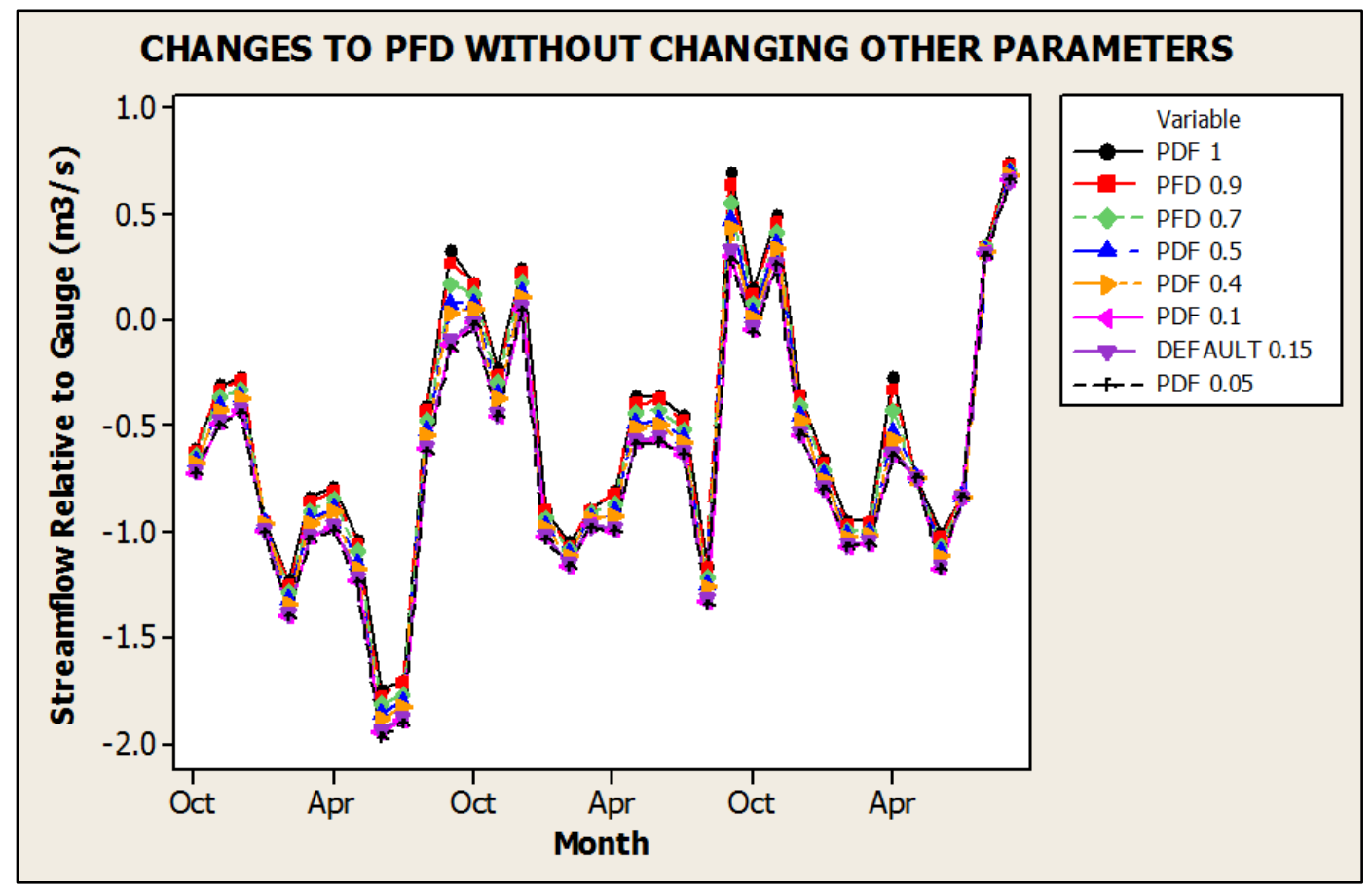

Figure 9. The Relationship of Streamflow Relative to Gauge (Absolute) with Change in Preferred Flow Direction (PFD)

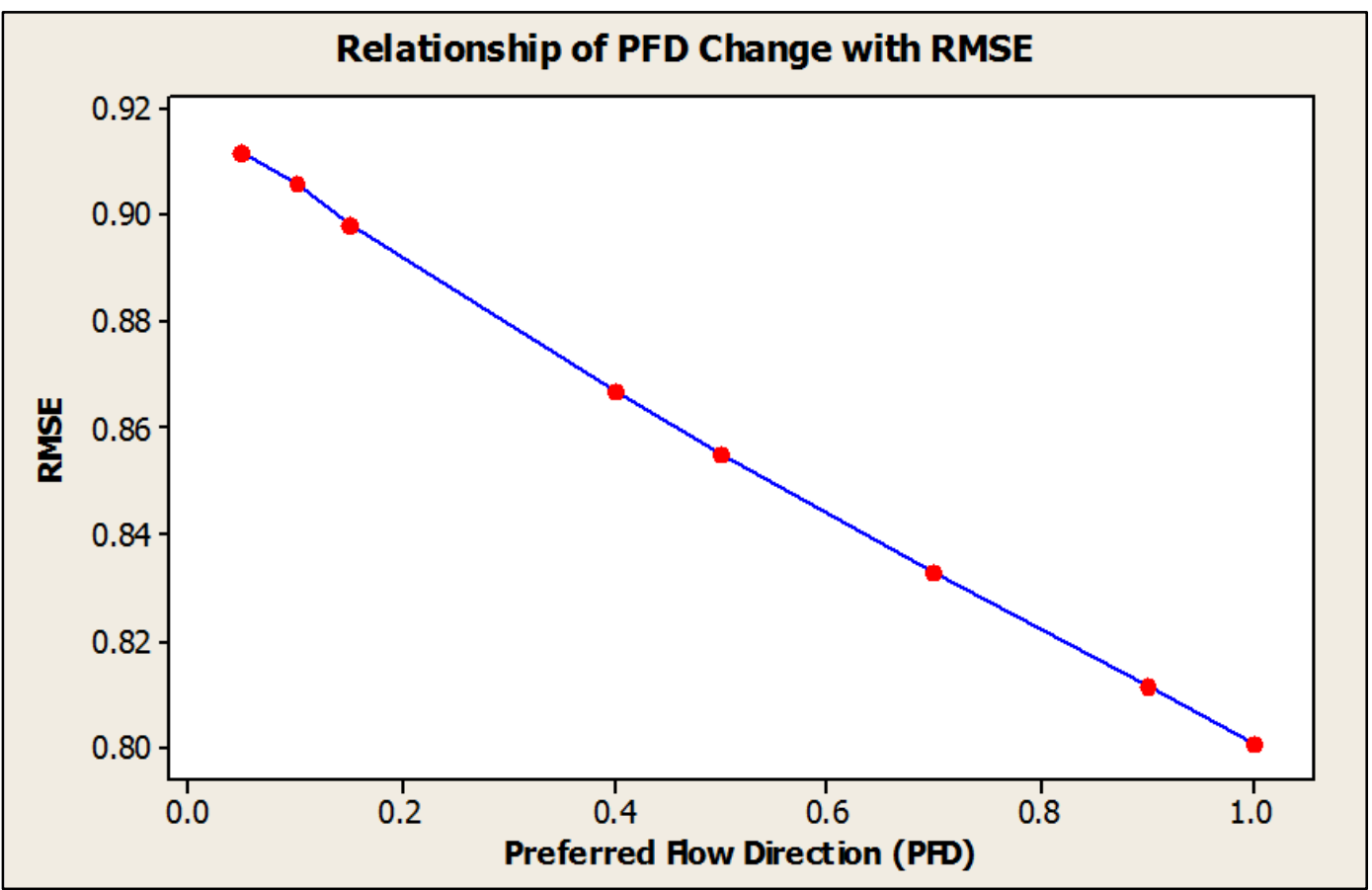

Figure 10. The Relationship of PFD with Root Mean Square Error (RMSE) value 


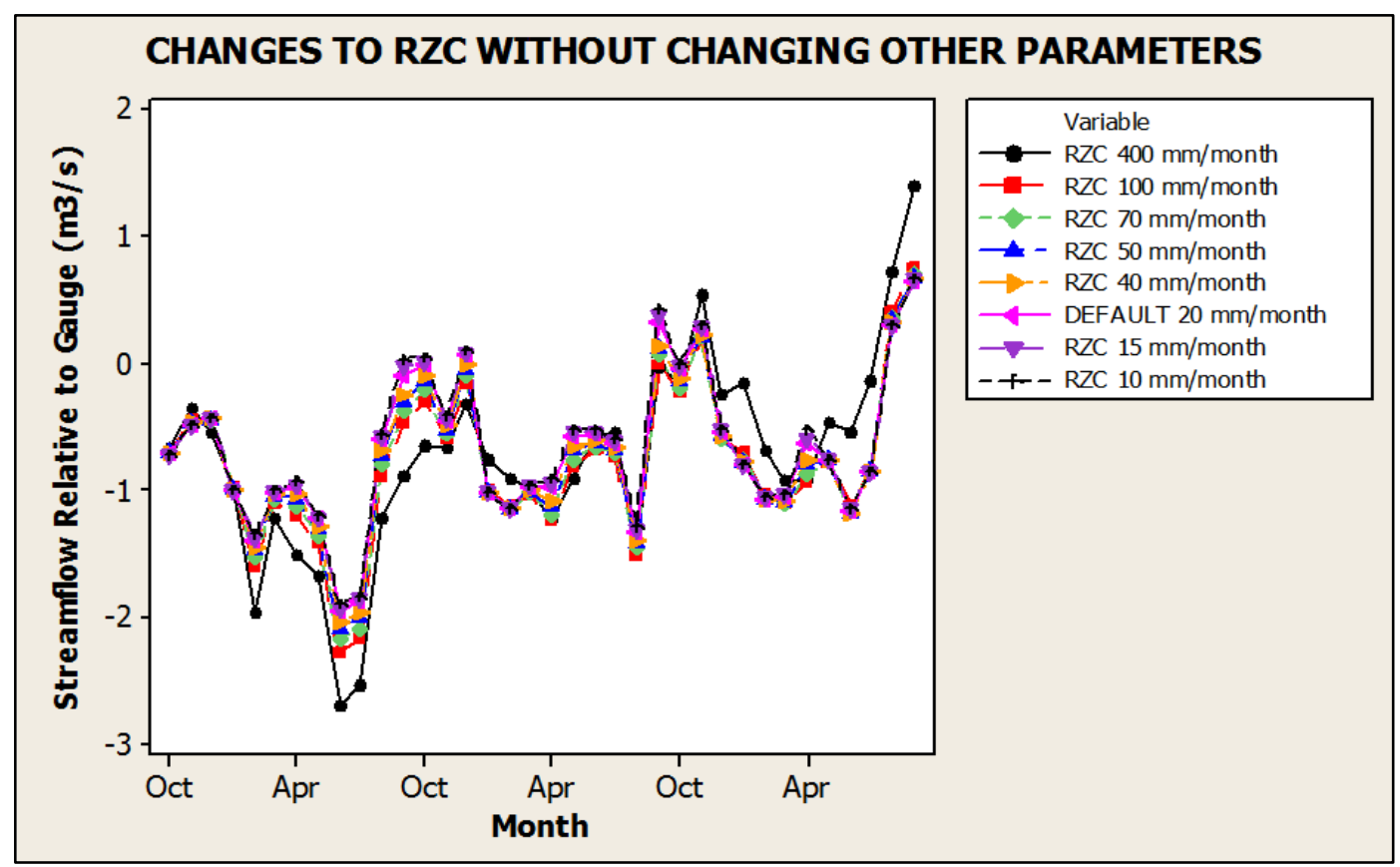

Figure 11. The Relationship of Streamflow Relative to Gauge (Absolute) with Change in Root Zone Conductivity (RZC)

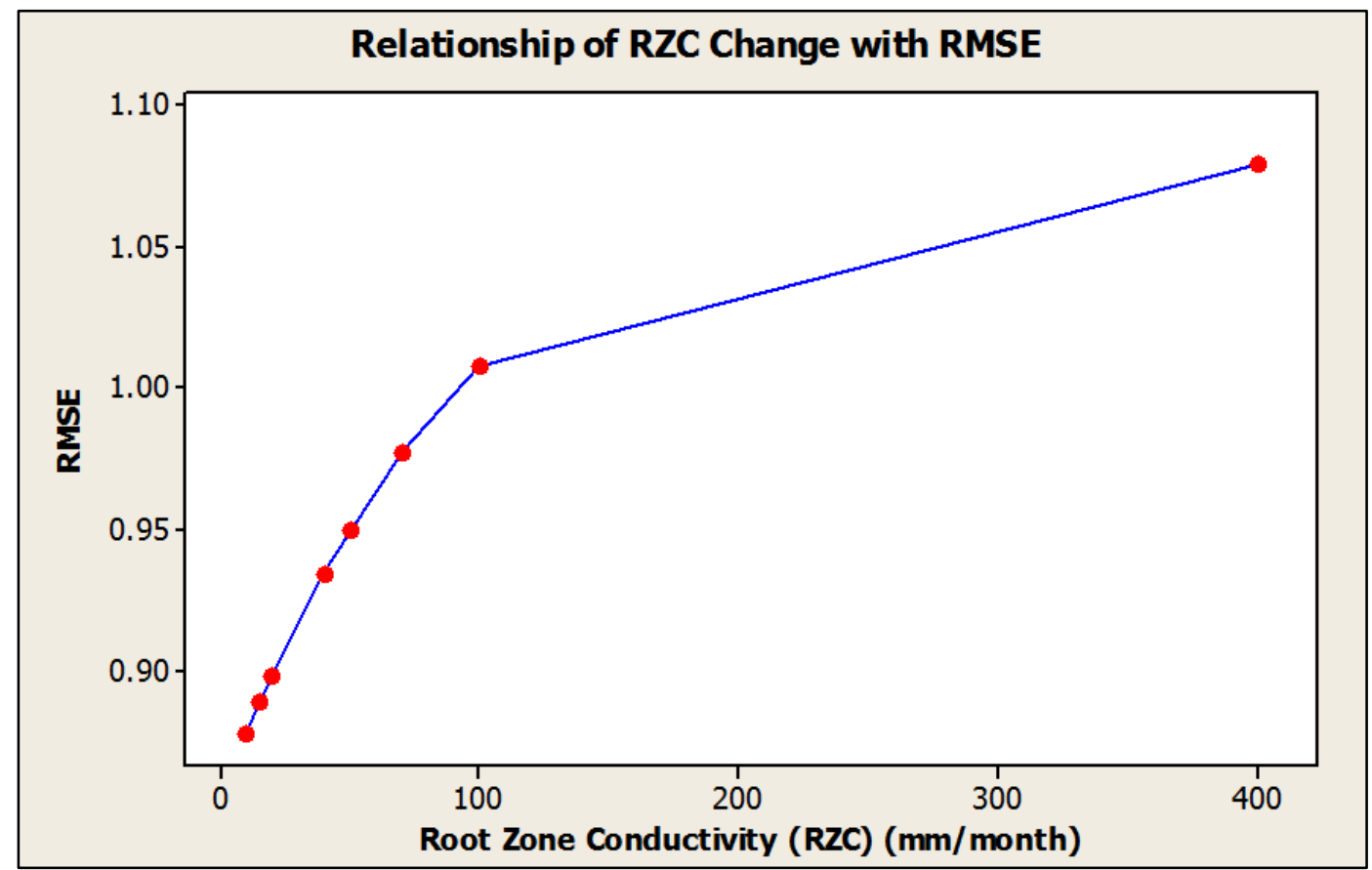

Figure 12. The Relationship of RZC with Root Mean Square Error (RMSE) value

\subsubsection{Changes in Root Zone Conductivity (RZC)}

The root zone conductivity (RZC) value is defined as the conductivity level of the root zone (top "bucket") at relative storage $\mathrm{Z}_{1}=1.0$ or full saturation. In this condition, preferred flow direction will be separated between interflow and flow to the subsoil. Different types of soil classes will cause variations in the RZC value.

In Figure 11, it can be seen the monthly streamflow relative to gauge values from 2012-2014 for several scenarios of RZC values.

The trend of changes in the root zone of conductivity (RZC) has an RMSE trend which tends to decrease along with the decrease in the value of the root zone of conductivity as shown in Figure 12. The RZC value is very influential on interflow and percolation, so when the RZC value is large, the flow rate will be smaller and vice versa. When the simulation discharge is lower than the observed RZC, the change in RZC does not significantly change the simulation discharge, but on the contrary, when the 
simulated discharge is greater than the observed RZC, the change is very significant.

\subsubsection{Changes in Deep Conductivity (DC)}

The value of deep conductivity (DC) is defined as the conductivity level of the deep layer at relative storage $Z_{2}=$ 1.0 or full saturation. Base flow transmission is controlled by this value. For the catchment area, this is given as a single value and it is not vary on different soil class type. When the DC value is increase, the baseflow value will increase too. If the research location has a backflow link to the groundwater node, then this value is ignored.

In Figure 13, it can be seen the monthly streamflow relative to gauge values from 2012-2014 for several scenarios of DC values.

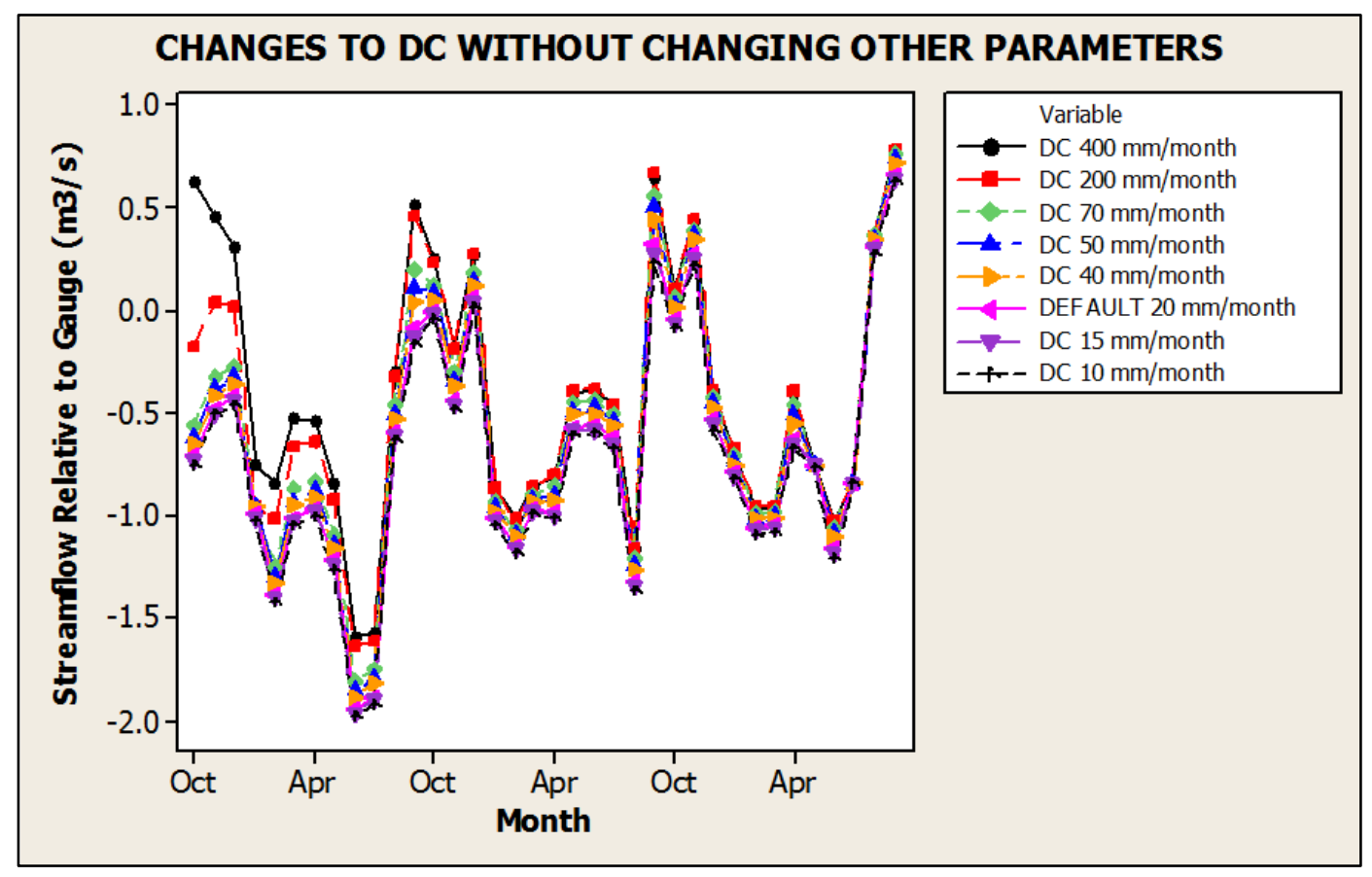

Figure 13. The Relationship of Streamflow Relative to Gauge (Absolute) with Change in Deep Conductivity (DC)

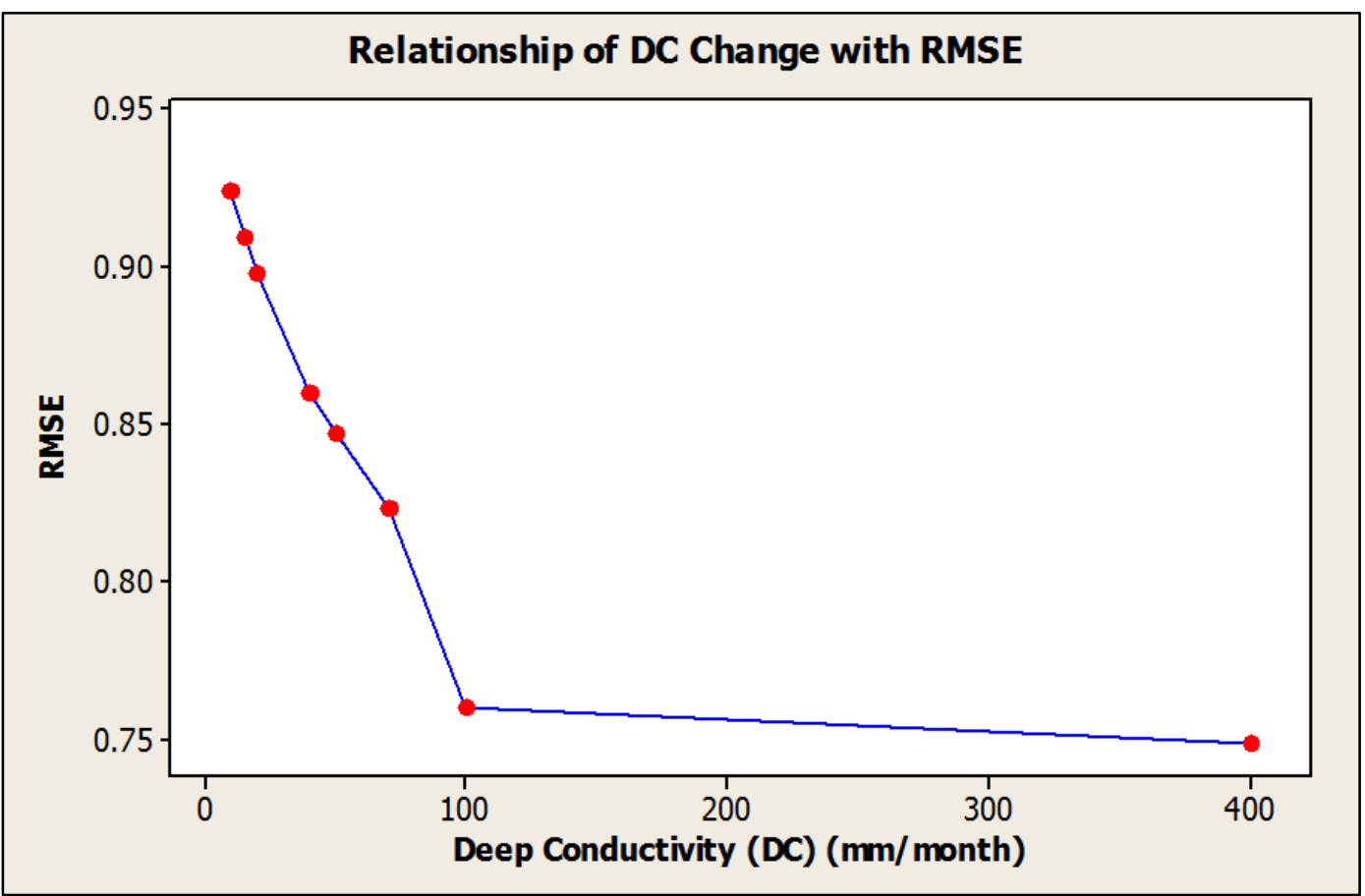

Figure 14. The Relationship of DC with Root Mean Square Error (RMSE) value 
The trend of changes in deep conductivity (DC) has an RMSE trend that tends to decrease as the value of deep conductivity increases. DC value is very influential on interflow and percolation. When the DC value is large, the baseflow increases and the surface runoff discharge decreases. Changes in DC values are not more significant than RZC values because DC values cannot vary for each type of land use.

\subsubsection{Changes in Resistance Runoff Factor (RRF)}

The resistance runoff factor (RRF) value is defined as the control surface runoff response. The RRF value is influenced by several factors including the catchment area index and land slope. The surface runoff value tends to decrease at higher RRF values (range 0 to 1000). Variations in the type of soil class also affect the RRF value.

In Figure 15, it can be seen the monthly streamflow relative to gauge values from 2012-2014 for several scenarios of RRF values.

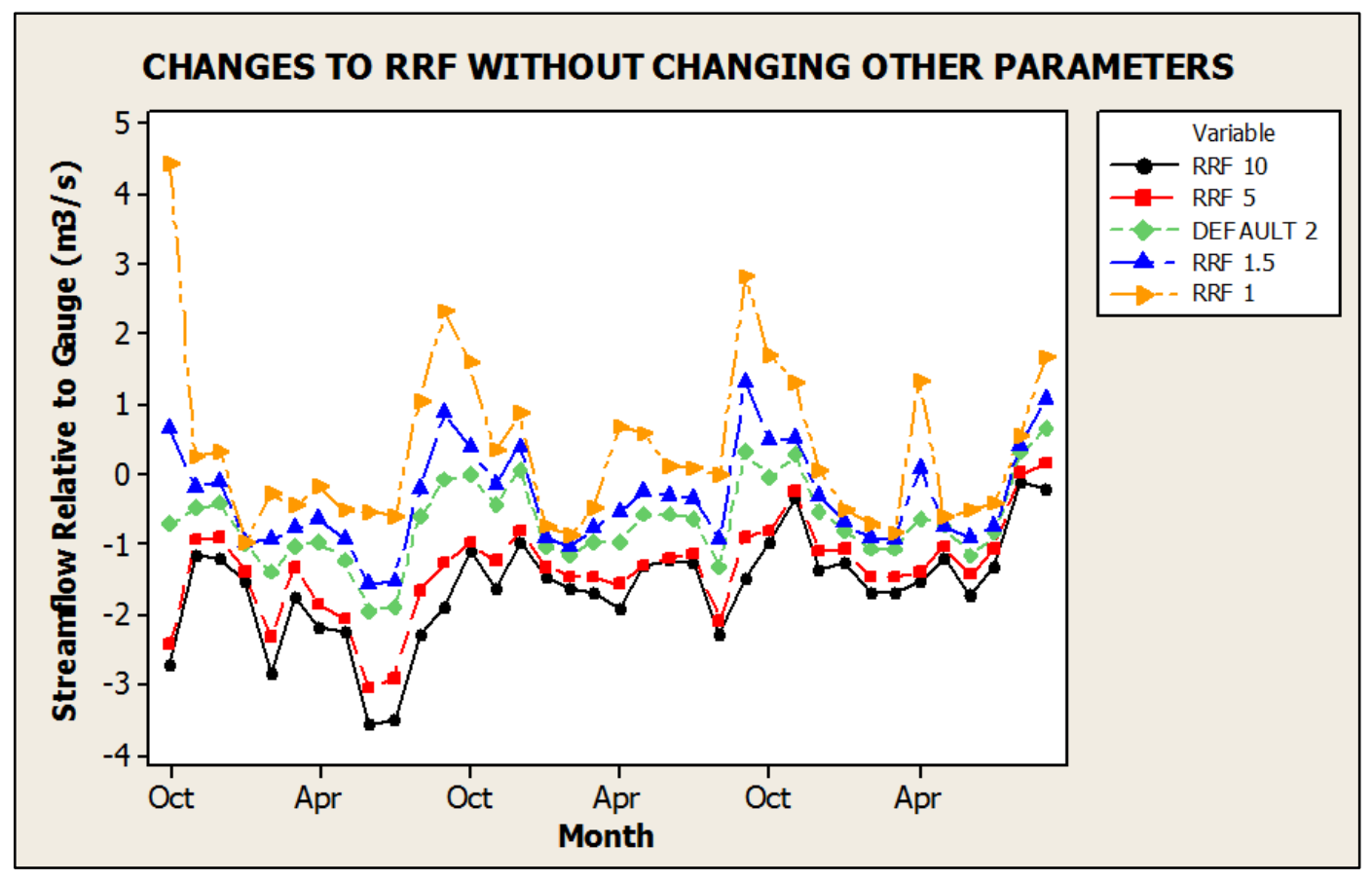

Figure 15. The Relationship of Streamflow Relative to Gauge (Absolute) with Change in Resistance Runoff Factor (RRF)

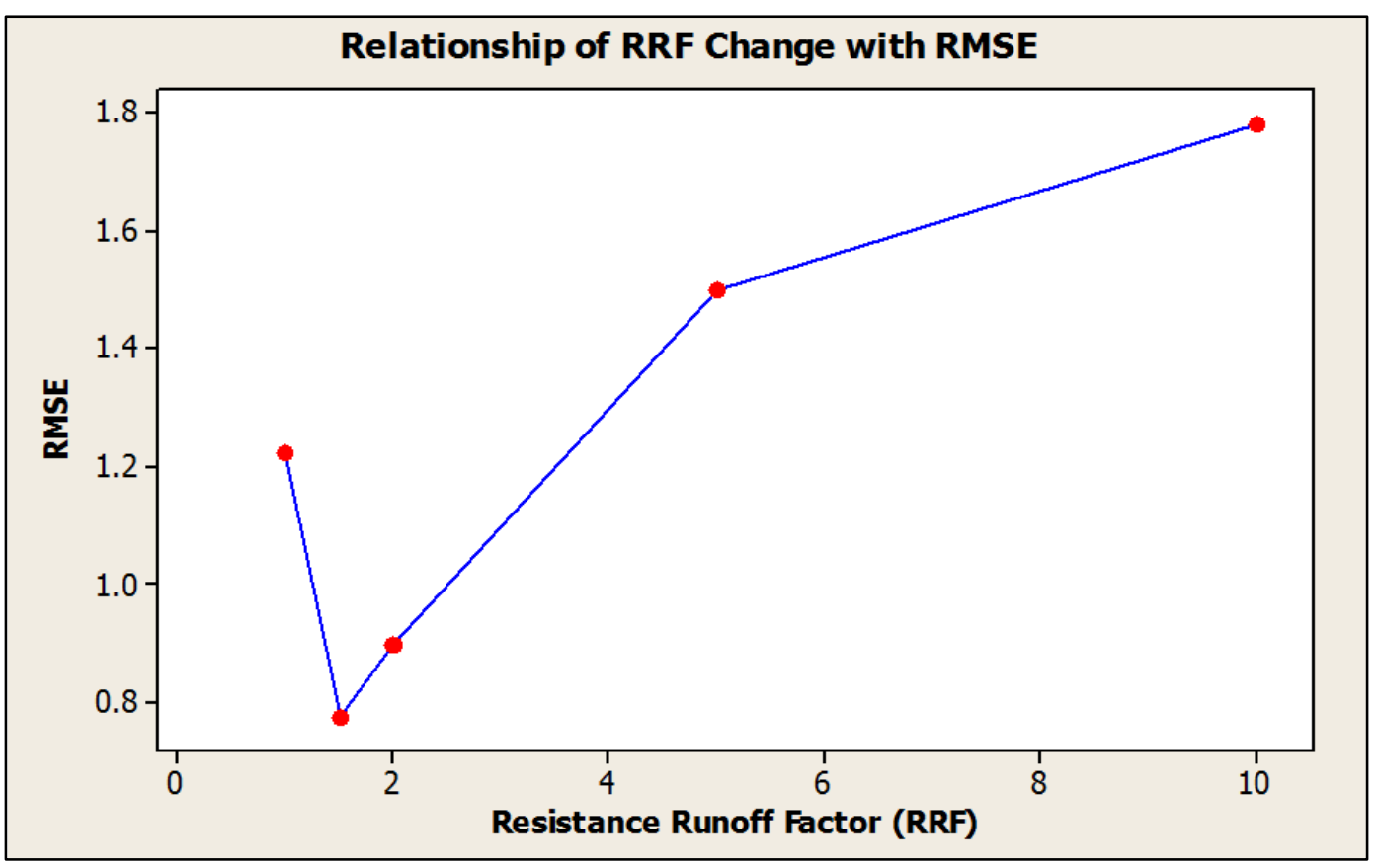

Figure 16. The Relationship of RRF with Root Mean Square Error (RMSE) value 
The trend of changes in the resistance runoff factor (RRF) has a trend that is almost the same as the change in $\mathrm{Z} 1$ with the optimum value (simulation discharge approaching the observation discharge) ranging from 1.5, where the change in RRF from 10 to 1.5 the RMSE (root mean square error) value decreases and increases at the change to 1 as shown in Figure 16. Changes in RRF very significantly change the simulation discharge value when the RRF is large the simulation discharge can be very small and when the RRF is large it can make the simulation discharge large.

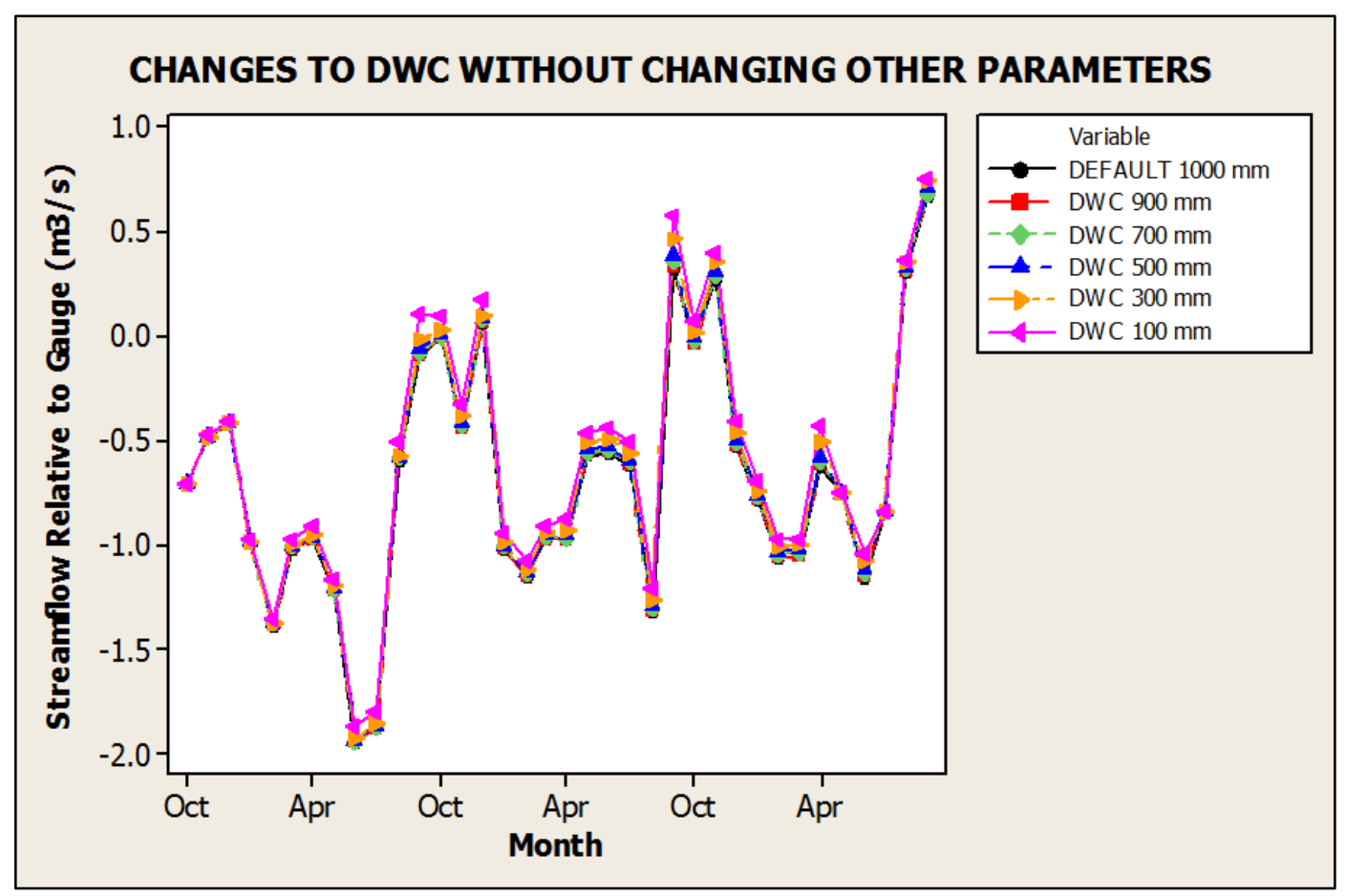

Figure 17. The Relationship of Streamflow Relative to Gauge (Absolute) with Change in Deep Water Capacity (DWC)

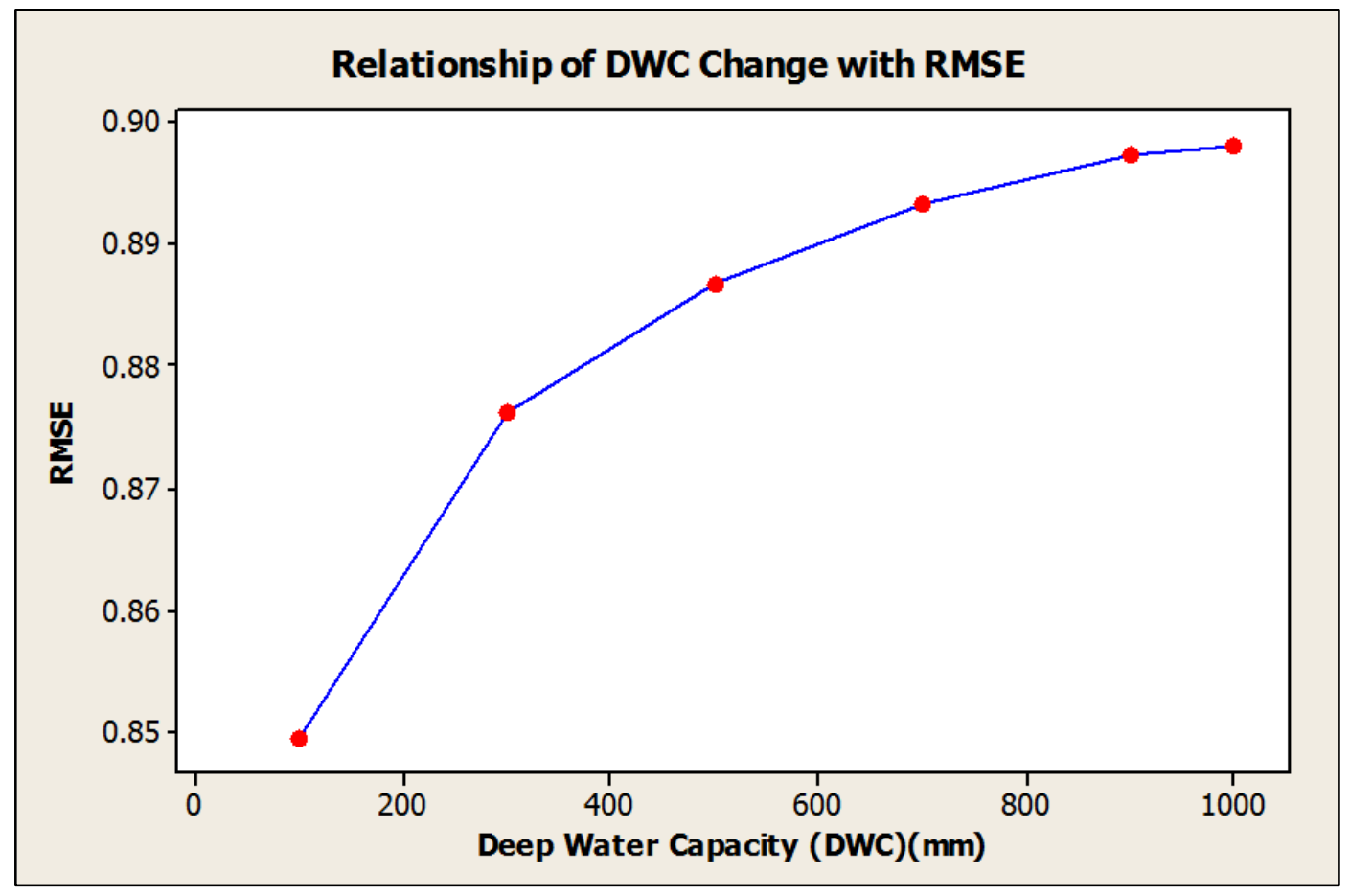

Figure 18. The Relationship of DWC with Root Mean Square Error (RMSE) value 


\subsubsection{Changes in Deep Water Capacity (DWC)}

The value of deep water capacity (DWC) is defined as the effective water holding capacity for the subsoil and deep (bottom "bucket"), represented in $\mathrm{mm}$. For the catchment area, this is given as a single value and it is not vary on different soil class type. If the research location has a backflow link to the groundwater node, this value can be ignored.

In Figure 17, it can be seen the monthly streamflow relative to gauge values from 2012-2014 for several scenarios of DWC values.

The trend of changes in the RMSE DWC tends to decrease along with the decreasing value of the DWC as shown in Figure 18. This may happen because the SWC value used is $1000 \mathrm{~mm}$ which is the maximum value so that if the DWC value is large, the discharge will be smaller. So the values of DWC and SWC are closely related.

\subsection{Optimum Parameter Value Used}

After performing the sensitivity analysis, the reliability value of the model was tested with values of R, IoA, Nash, and RMSE [28]. After being considered feasible, the sensitivity analysis process was stopped, and the optimum parameter values used were shown in Table 4.

Table 4. Optimum Parameter Value Used

\begin{tabular}{|c|c|}
\hline Parameter & Used Value \\
\hline $\mathrm{Z}_{1}$ & $25 \%$ \\
\hline $\mathrm{Z}_{2}$ & $65 \%$ \\
\hline Deep Water Capacity (DWC) & $900 \mathrm{~mm}$ \\
\hline Deep Conductivity (DC) & $75 \mathrm{~mm} / \mathrm{month}$ \\
\hline Resistance Runoff Factor (RRF) & 2 \\
\hline Root Zone Conductivity (RZC) & $75 \mathrm{~mm} / \mathrm{month}$ \\
\hline Soil Water Capacity (SWC) & $900 \mathrm{~mm}$ \\
\hline Preferred Flow Direction (PFD) & $0.4-0.9$ \\
\hline
\end{tabular}

\subsection{Model Reliability Value}

Based on the calibration results, the $\mathrm{R}$ value is 0.743 and based on Tables 1 and 2 it can be shown that the results of the simulation discharge model with the observation discharge show a high correlation, where the simulated discharge value is close to the observed discharge [27]. Then the Nash Sutcliffe Efficiency coefficient at the time of calibration shows a satisfactory model with a value of 0.512 [26]. Then when calibrating the Index of Agreement value which shows a high level of compatibility with a value of 0.848 . In addition to the model's reliability value, the Mean Bias Error value is also calculated where at the time of calibration the mean bias error value shows a negative result with a value still below 0.20 this shows that the simulation model has an average discharge value that is lower than the observed discharge.
Based on the calibration results, it can be concluded that the model is sufficient to represent the actual situation and can be used further for the simulation process of integrated water resources management scenarios.

Table 5. Model Reliability Value

\begin{tabular}{|c|c|}
\hline Reliability Test & Calibration Value \\
\hline Correlation Coefficient & $\begin{array}{c}\left(\mathrm{R}^{2}\right): 0.553 \\
(\mathrm{R}): 0.743\end{array}$ \\
\hline Index of Agreement & 0.848 \\
\hline Nash Sutcliffe Efficiency coefficient & 0.512 \\
\hline Root Mean Square Error (RMSE) & 0.563 \\
\hline Mean Bias Error & -0.088 \\
\hline
\end{tabular}

\section{Conclusions}

Based on the results and discussion several things can be concluded as follows.

1. In the sensitivity analysis process for several calibration parameters of the WEAP model, it can be seen that there are several similar characteristics including $\mathrm{Z}_{1}$, DWC, RRF, RZC (change in a parameter value is directly proportional to the RMSE value, the greater the parameter value, the greater the RMSE value obtained) and $Z_{2}$, DC, SWC, PRD (change in a parameter value is inversely proportional to the RMSE value, the larger the parameter value, the smaller the RMSE value obtained).

2. After performing a sensitivity analysis, the optimum parameters are determined. The optimum value of $\mathrm{Z}_{1}$ is $25 \%, Z_{2}$ is $65 \%$, DWC (Deep Water Capacity) 900 $\mathrm{mm}$, DC (Deep Conductivity) is $75 \mathrm{~mm} / \mathrm{month}$, RRF (Resistance Runoff Factor) is 2, RZC (Root Zone Conductivity) is $75 \mathrm{~mm} / \mathrm{month}$, SWC (Soil Water Capacity) is $900 \mathrm{~mm}$, and PFD (Preferred Flow Direction) range on $0.4-0.9$. After the sensitivity analysis was carried out, the efficiency coefficient of the Nash Sutcliffe model was obtained 0.512 which was satisfactory. The Index of Agreement and the correlation coefficient of calibration also show good results with values of 0.848 and 0.743 . From these results, it can be concluded that the WEAP model for the Unda watershed is satisfactory.

\section{REFERENCES}

[1] N. Hamidon et al., "Prediction of future climate change for rainfall in the upper kurau river basin, perak using statistical downscaling model (SDSM)," Civil Engineering and Architecture, vol. 7, no. 6, pp. 33-42, 2019, doi: 10.13189/cea.2019.071404.

[2] A. Asadpour, "Re-designing Urban Stream Landscape by Investigating the Citizens' Preference Matrix," Civil Engineering and Architecture, vol. 5, no. 4, pp. 152-160, 2017, doi: 10.13189/cea.2017.050404. 
[3] T. Chanapathi, S. Thatikonda, and S. Raghavan, “Analysis of rainfall extremes and water yield of Krishna river basin under future climate scenarios,” J. Hydrol. Reg. Stud., vol. 19, no. October, pp. 287-306, 2018, doi: 10.1016/j.ejrh.20 18.10.004

[4] A. Nahwani and A. E. Husin, "Water network improvement using infrastructure leakage index and geographic information system," Civil Engineering and Architecture, vol. 9, no. 3, pp. 909-914, 2021, doi: 10.13189/cea.2021.090333.

[5] F. P. Suprobo and R. D. Mutfianti, "Environmental innovation model with product and outcomes dimension of green kampung in surabaya city," Civil Engineering and Architecture, vol. 9, no. 1, pp. 1-8, 2021, doi: 10.13189/cea.2021.090101.

[6] M. Touseef, L. Chen, and W. Yang, "Assessment of surfacewater availability under climate change using coupled SWAT-WEAP in hongshui river basin, China," ISPRS Int. J. Geo-Information, vol. 10, no. 5, 2021, doi: 10.3390/ijgi10050298.

[7] S. Agarwal, J. P. Patil, V. C. Goyal, and A. Singh, "Assessment of Water Supply-Demand Using Water Evaluation and Planning (WEAP) Model for Ur River Watershed, Madhya Pradesh, India,” J. Inst. Eng. Ser. A, vol. 100, no. 1, pp. 21-32, 2019, doi:10.1007/s40030-0180329-0.

[8] D. Abera Abdi and T. Ayenew, "Evaluation of the WEAP model in simulating subbasin hydrology in the Central Rift Valley basin, Ethiopia,” Ecol. Process., vol. 10, no. 1, 2021, doi: 10.1186/s13717-021-00305-5.

[9] D. Mena, A. Solera, L. Restrepo, M. Pimiento, M. Cañón, and F. Duarte, "An analysis of unmet water demand under climate change scenarios in the Gualí river basin, Colombia, through the implementation of hydro-bid and weap hydrological modeling tools," J. Water Clim. Chang., vol. 12, no. 1, pp. 185-200, 2021, doi: 10.2166/wcc.2019.118.

[10] M. Rajendran, "Runoff Prediction in an Ungauged Catchment of Upper Deduru Oya Basin, Sri Lanka: A Comparison of HEC-HMS and WEAP Models,” Int. J. Progress. Sci. Technol., no. January, pp. 121-129, 2020.

[11] M. W. Jayantari, W. Wardoyo, and M. A. Maulana, "Satellite data use in the WEAP Model as an evaluation of Water Availability in Unda River Basin," IOP Conf. Ser. Earth Environ. Sci., vol. 389, no. 1, 2019, doi: 10.1088/1755-1315/389/1/012027.

[12] D. Yates, J. Sieber, D. Purkey, and A. Huber-Lee, "WEAP21 - A demand-, priority-, and preference-driven water planning model. Part 1: Model characteristics,” Water Int., vol. 30, no. 4, pp. 487-500, 2005, doi: $10.1080 / 02508060508691893$.

[13] I. Hagan, "Modelling the Impact of Small Reservoirs in the Upper East Region of Ghana,” Lund University, 2007.

[14] M. P. McCartney and R. Arranz, "Evaluation of Historic, Current and Future Water Demand in the Olifants River Catchment, South Africa,” Colombo, 2007.

[15] Stockholm Environment Institute, "WEAP Selected Publications,” 2021.https://www.weap21.org/index.asp?ac tion=216\&NewLang=EN (accessed Oct. 29, 2021).
[16] I. G. A. P. Eryani, A. M. A. Manan, and M. W. Jayantari, "Comparative Analysis of Watershed Characteristics in Bali Province for Sustainable Water Resources Management,” Indones. J. Urban Environ. Technol., vol. 4, no. 2, p. 210, 2021, doi: 10.25105/urbanenvirotech.v4i2.88 62.

[17] B. Nijssen and L. A. Bastidas, "Land-Atmosphere Models for Water and Energy Cycle Studies,” Encycl. Hydrol. Sci., pp. 1-13, 2005, doi: 10.1002/0470848944.hsa212.

[18] S. Sorooshian and W. Chu, "Review of parameterization and parameter estimation for hydrologic models," L. Surf. Obs. Model. Data Assim., no. 2001, pp. 127-140, 2013, doi: 10.1142/9789814472616_0005.

[19] Z. Kala, "Sensitivity analysis in probabilistic structural design: A comparison of selected techniques,” Sustain., vol. 12, no. 11, 2020, doi: 10.3390/su12114788.

[20] J. Gou et al., "Sensitivity Analysis-Based Automatic Parameter Calibration of the VIC Model for Streamflow Simulations Over China,” Water Resour. Res., vol. 56, no. 1, pp. 1-19, 2020, doi: 10.1029/2019WR025968.

[21] D. Tolley, L. Foglia, and T. Harter, "Sensitivity Analysis and Calibration of an Integrated Hydrologic Model in an Irrigated Agricultural Basin With a Groundwater-Dependent Ecosystem," Water Resour. Res., vol. 55, no. 9, pp. 7876-7901, 2019, doi: 10.1029/2018WR024209.

[22] D. H. Kouchi, K. Esmaili, A. Faridhosseini, S. H. Sanaeinejad, D. Khalili, and K. C. Abbaspour, "Sensitivity of calibrated parameters and water resource estimates on different objective functions and optimization algorithms," Water (Switzerland), vol. 9, no. 6, pp. 1-16, 2017, doi: 10.3390/w9060384.

[23] S. Sorooshian, Q. Duan, and V. Gupta, "Calibration of Rainfall-Runoff Models. Application of Global Optimization to the Sacramento Soil Moisture Accounting Model,” Water Resour. Res., vol. 29, pp. 1185-1194, 1993.

[24] M. S. Al-Ghadi, W. H. M. W. Mohtar, S. F. M. Razali, and A. El-Shafie, "Hydraulic modelling analysis for road stormwater drainage evaluation under rcps based rainfall data," Civil Engineering and Architecture, vol. 8, no. 6, pp. 1335-1349, 2020, doi: 10.13189/cea.2020.080617.

[25] K. Beven, "Changing Ideas in Hydrology - The case of Physically Based Models,” J. Hydrol., vol. 105, pp. 157172, 1989.

[26] Y. G. Motovilov, L. Gottschalk, K. Engeland, and A. Rodhe, "Validation of a Distributed Hydrolofical Model Against Spatial Observations,” Elsevier Agric. For. Meteorol., vol. 98, pp. 257-277, 1999.

[27] S. Sutikno, M. F., and M. M., "Calibration and Validation of Rain-flow Hydrology Models Using Satellite Data,” in Conference: XXXI HATHI Annual Scientific Meeting (PIT), 2014, doi: http://dx.doi.org/10.13140/RG.2.1.2287.5689.

[28] A. F. Ikechukwu and N. Onyeka, "Validation of Semi-empirical Models for the Prediction of Swelling Stress for Compacted Unsaturated Expansive Soils,” Civil Engineering and Architecture, vol. 9, no. 5, pp. 1640-1658, 2021, doi: 10.13189/cea.2021.090533. 